\title{
MEDICAL PROFESSIONALISM AND THE SUCCESS IN MEDICAL SCHOOL, A PRIMER FOR NEW MEDICAL STUDENTS
}

\author{
MUHAMMAD FAROOQ AFZAL \\ Department of Surgery, Postgraduate Medical Institute/Ameer-ud-Din Medical College/ \\ Lahore General Hospital, Lahore
}

\begin{abstract}
How to cite this article: Afzal MF. Covid-19: Medical professionalism and the success in medical school, a primer for new medical students. Pak Postgrad Med J 2020;31(1): 1-2

DOI: HTTPS//DOI.ORG/10.51642/ppmj.v31i01.396

This is an Open Access article distributed under the terms of the Creative Commons Attribution License (http://creativecommons.org/licenses/by/3.0), which permits unrestricted use, distribution, and reproduction in any medium, provided the original work is properly cited.
\end{abstract}

Correspondence to: Muhammad Farooq Afzal,

Professor, Department of Surgery,

Postgraduate Medical Institute/Ameer-ud-Din Medical

College/Lahore General Hospital, Lahore, Pakistan.

\section{Email: mfarooqafzal@yahoo.com}

Traditionally, doctors are one of the most respected professionals and they are considered "Messiah" for centuries. But recently, there is a lot of negative impression in the media about doctors who are blamed to be neither competent nor good humans and titles like "Qatal" and Greedy etc. are used leading to deterioration of the image of doctors in the society. Apart from other reasons of this negative image, many believe that lack of professionalism among the doctors is the key issue and therefore, the solution lies in cultivating the values of professionalism among medical students from the day one of their medical school.

Let's discuss about medical professionalism by answering these three questions. What is medical professionalism? Why we need it? How can we develop it?

\section{What is Professionalism?}

Our profession is to heal. we learn in medical school not only the knowledge and, skills but attitudes and behaviors that enable us to help people heal.

Traditionally, doctors try to solve three fundamental questions in daily practice. ${ }^{1}$.

1. The diagnostic question, what is the problem of the patient?

2. The therapeutic question, what can be done for this patient?
3. The prudential question, what should be done for this patient?

It is difficult to define medical professionalism because it has various perspectives but few of the prevailing definitions are:

"A set of values, behaviors, and relationships that underpins the trust the public has in doctors." (RCP UK) ${ }^{2}$

"Professional competence is the habitual and judicious use of communication, knowledge, technical skills, values emotions, and reflection for the welfare of the fellow ailing human beings". ${ }^{3}$

Whatever the definition, the three underlying cardinal principles for medical professionalism are ${ }^{1}$

1. Patient welfare, the interest of the patient is supreme.

2. Patient autonomy, the patient is the ultimate decision maker.

3. Social justice, considering the need of the patient and the available resources.

The personal values and attributes of a good professional can be remembered by this simple mnemonic of $\mathrm{ABCDE}$, where A is for Altruism and Accountability, B for Behavior, C for Communication, D for Duty and Dedication, E for Ethics and Excellence.

\section{Why we need Professionalism?}

We need Professionalism not only to improve the patient related outcomes but to produce successful doctors. Good doctors are the ones who score high on the cognitive part, knowledge, and technical skills but the successful ones are those who are good in the non-cognitive part 
especially the communication, empathy, integrity, and humanism. ${ }^{1}$

\section{How can we develop Professionalism?}

Read, observe, and practice. Looking for role models in own institute and in the medical profession and emulating them is one way. The other way is to get feedback from trusted mentors and reflect on one's experiences daily. Teachers can teach the students about medical professionalism by role modelling, tutorials, demonstrations, and workshop and can assess these behaviors as well using 360-degree feedback or other methods. ${ }^{2}$

While success in medical school is mostly having talent and attaining good grades and technical skills but the journey towards lifelong success cannot be achieved by high IQ or talent alone but is dependent on grit, passion and perseverance. ${ }^{3}$

Failure is also important part of success. During your training, you can see failures and disappointments when you get low marks or didn't achieve higher grades. Long term studies on student's achievements have shown that the persons who will succeed in the long run are the ones who will show, grit, curiosity and resilience ${ }^{5}$ and the desire for lifelong learning and continuous selfimprovement.
When you get sick, which doctor you will like to go; My message is be that best doctor by whom you want your mother or kid to be treated.

\section{REFERENCES}

1. Kirk LM. Professionalism in medicine: definitions and considerations for teaching. Proc (Bayl Univ Med Cent). 2007;20(1):13-16.

2. Advancing medical professionalism, http://www. replond.ac.uk

3. Epstein RM, Hundert EM. Defining and assessing professional competence. JAMA. 2002;287(2):226-235.

4. Duckworth AL, Peterson C, Matthews MD, Kelly DR. Grit: perseverance and passion for long-term goals. J Pers Soc Psychol. 2007;92(6):1087-1101.

5. Thompson G, McBride RB, Hosford CC, Halaas G. Resilience among medical students: the role of coping style and social support. Teach Learn Med. 2016;28(2):174-182. 